\title{
HEADACHE SECONDARY TO HAEMORRHAGIC STROKE RESEMBLING PAROXYSMAL HEMICRANIA
}

\author{
Rodrigo Bazan', Leila Azevedo de Almeida', Fernando Coronetti Gomes da Rocha ${ }^{2}$, \\ Cesar Noronha Raffin ${ }^{3}$, Ronaldo Guimarães Fonseca ${ }^{4}$
}

The association between hemicrania and autonomic phenomena is the main aspect shared by a group of headaches called trigemino autonomic cephalalgias (TAC's)'. Their pathophysiology is not entirely known. Trigeminal and intermediary nerves of Wrisburg are involved as well as structures and brainstem connections and posterior hypothalamus'. Belonging to TAC's, paroxysmal hemicrania (PH) was described by Sjaastad and Dale, in 1974, as a variant of cluster headaches, characterized by similar crises with a lower duration, higher frequency and dramatic response to indomethacin. Associations of structural lesions with paroxysmal hemicranias, other trigemino autonomic cephalalgias and migraine-like headaches have been described. Such reports corroborate the view according to which posterior hypothalamus and brainstem play a major role in the pathophysiology of these groups of headaches ${ }^{4}$.

We report a case of a patient with a headache resembling TAC's but secondary to intraparenchymatous hematoma in brainstem, with an expressive response to indomethacin.

\section{CASE}

Male, 51 years old, caucasian, reported having shown three to four attacks a week for three months of strictly high intensity right hemicrania, mostly around the ocular globe, with sharp pains and average duration of 20 minutes. The crises of headache occurred four to six times a day, predominantly at night, but rarely awakening because of pain. The headache was associated with lacrimation, conjunctival hyperemia, palpebral edema and nasal congestion, ipsilateral to hemicrania. In his personal history he had severe artery hypertension, smoking, and haemorrhagic stroke (HCVA), clinically treated, occurring ten days before the onset of headache. He denied having previous headaches or familial history of headache.

Neurological examination showed right hypertonic and hyper-reflex hemiparesia. Magnetic scanning (MRI) was compatible to intraparenchymatous hematoma in brainstem, in pons topography, mostly in anterior and left regions, and midbrain (Figs 1, 2 and 3).

The patient was first treated with amitriptyline, $50 \mathrm{mg} /$ day, and reevaluated a month later. No clinical improvement was obtained. At that occasion, indomethacin was administered orally
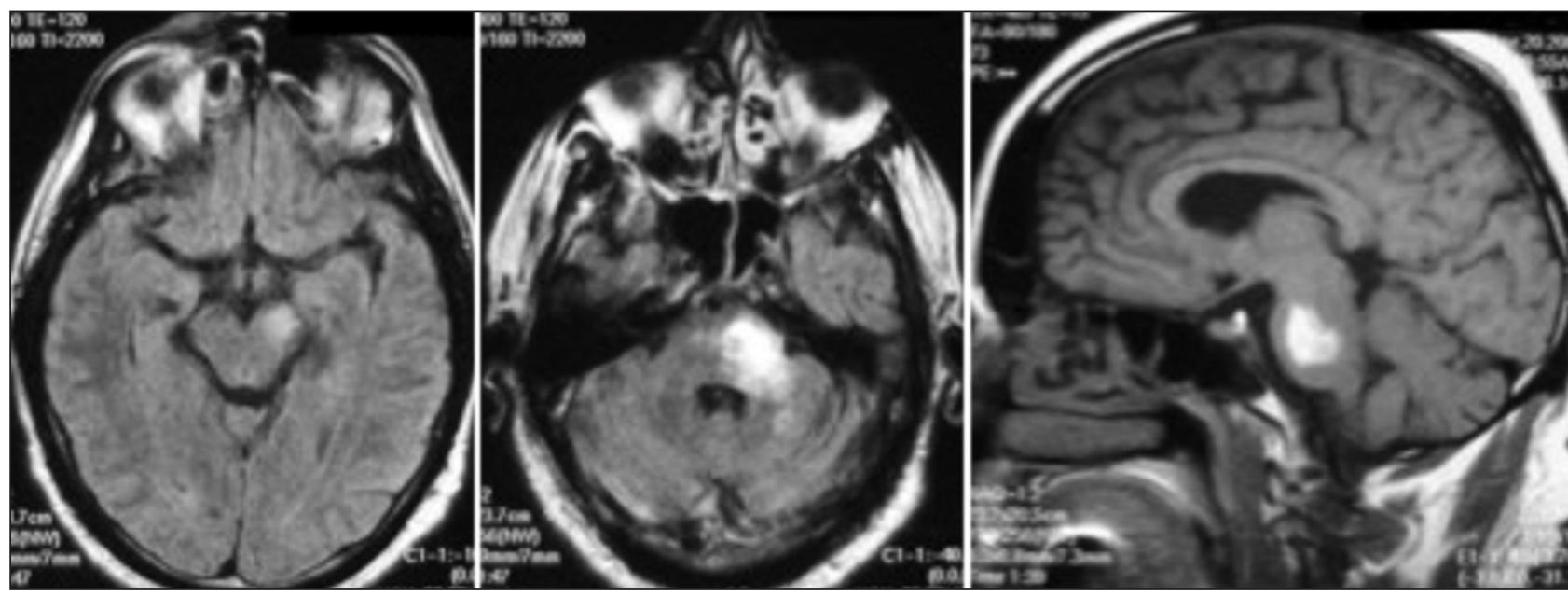

Figs 1, 2 and 3. Hemorrhagic lesions shown in magnetic ressonance imaging in midbrain and pons topography (brainstem), respectively.

\section{CEFALÉIA SECUNDÁRIA A ACIDENTE VASCULAR ENCEFÁLICO HEMORRÁGICO SIMULANDO HEMICRANIA PAROXÍSTICA}

Botucatu Medical School, UNESP, Botucatu SP, Brazil: 'Neurologist; ${ }^{2}$ Assistant Professor in Neurology; ${ }^{3}$ Assistant Professor in Neurology of Meridional Hospital, Espírito Santo; ${ }^{4}$ Assistant Professor in Neurology and Chief of Headache Center, Botucatu.

Received 6 September 2007, received in final form 21 July 2008. Accepted 4 August 2008.

Dr. Rodrigo Bazan - Neurology Departament / Botucatu Medical School / UNESP - 18610-180 Botucatu SP - Brasil. E mail- bazan.r@terra.com.br 
at a total daily dose of $150 \mathrm{mg}$ considering a diagnostic hypothesis of paroxysmal hemicrania secondary to intraparenchymatous hematoma in brainstem. It evolved in few days with total remission of signs and symptoms. After four months, reduction and removal of medication were scheduled. The patient has been asymptomatic up to the present date (48 months' follow-up).

\section{DISCUSSION}

We report the case of a patient with intense pain episodes, fulfilling the criteria diagnosed for paroxysmal hemicrania by the International Classification of Headache Disorders of the International Headache Society second edition', in a patient developing a hematoma in the brainstem, of higher location colateral to hemicrania. However, when a new headache occurs for the first time in a tight time relationship with a vascular disturbance, it is classified as a secondary headache attributed to this vascular disturbance; in our case, the headache was attributed to intracerebral hemorrhage ${ }^{1}$. We do not know of a similar case described in the English-language literature. There are few reports that point to brainstem structures, such as ventrolateral midbrain, rostral-dorso part of pons and bulb-pons junction, involved in the pathophysiopathy of hemicrania continua. ${ }^{5}$

MRI and positron emission tomography (PET) studies have shown that the grayish substance in the posteriorinferior hypothalamus is activated during trigemino autonomic cephalalgias ${ }^{6}$. On the other hand, clinical, PET and deep cerebral stimulation studies suggest that the rostral portion of the brainstem is essential to migraine pathophysiology, with emphasis on the role of periaqueductal gray substance contralateral to the pain episode ${ }^{7}$. However, a bigger activation in the aforementioned areas is not usually observed in TAC's. Some authors suggest that such a development of the brainstem is characteristic of migraines ${ }^{7}$. In the case described, we observed brainstem hematoma, in pons and midbrain topography, associated with the development of TAC's.

There are evidences of direct trigemino-hypothalamic paths and, reciprocally, of projections of the very posterior hypothalamus on neural activity of the trigeminal nuclei ${ }^{2}$. We question whether the involvement of this system of hypothalamic modulation on trigeminal nuclei may have favored the activation of trigeminofacial reflex in the brainstem and whether, as shown in literature, the posterior hypothalamus does not play a greater role as pacemaker in trigemino autonomic cephalalgias and is not the real generator. Considering the trigemino-facial activation as the final path, we also inquire to what extent this reflex is not stimulated by the presence of intraparenchymatous hematoma, with inflammatory response is induced by it (for that scope, the anatomical path would not have been injured by the hematoma) ${ }^{2,8,9}$. We also believe in the possible involvement of trigemino inhibitory unmodulated nociception, represented by diffuse nociceptive inhibitory control, involving the neurons of inhibitory nociception in the spinal and trigeminal dorsal horns $^{10}$. Finally we should stress the extension of bleeding toward the locus ceruleus region, one of the antinociceptive systems whose dysfunction can be associated with the compromising of the trigeminal inhibition.

Up to the present date, the patient has not developed a daily headache, as described in some people having structural lesions in pons and midbrain, in which there was a continual damage to structures having antinoceptive systems in the pathophysiology of evolution to chronic pain ${ }^{7,11}$.

\section{REFERENCES}

1. The international classification of headache disorders, $2^{\text {nd }}$ Ed (ICHD II). Cephalalgia 2004;24(Suppl 1):S1-S160.

2. Leone M. Deep brain stimulation in headache. Lancet Neurol 2006;5: 873-877.

3. Sjaastad O, Dale I. Evidence for a new (?) treatable headache entity. Headache 1974;14:105-108.

4. Speciali JG, Silva WF. Cefaléias. São Paulo: Lemos Editorial, 2002.

5. Matharu MS, Cohen AS, McGonigle DJ, Ward N, Frackowiak RS, Goadsby PJ. Posterior hypothalamic and brainstem activation in hemicrania continua. Headache 2004;44;747-761.

6. Leone M, Franzini A, Felisati G, et al. Deep brain stimulation and cluster headache. Neurol Sci 2005;26(Suppl 2):S138-S139.

7. Goadsby PJ. Neurovascular headache and a midbrain vascular malformation: evidence for a role of the brainstem in chronic migraine. Cephalalgia 2002;22:107-111.

8. Knight YE, Classey JD, Lasalandra MP, et al. Pattern of fos expression in the rostral medulla and caudal pons evoked by noxious craniovascular stimulation and periaqueductal gray stimulation in the cat. Brain Res 2005;1045:1-11.

9. Leira R, Castellanos M, Avarez-Sabín J, Diez-Tejedor E, Dávalos A, Castillo J. Stroke Project, Cerebrovascular Diseases Group of the Spanish Neurological Society. Headache in cerebral hemorrhage is associated with inflammatory markers and higher residual cavity. Headache 2005;45:1236-1243.

10. Piovesan EJ, Di Stani F, Kowacs PA, et al. Massaging over the greater occipital nerve reduces the intensity of migraine attacks. Arq Neuropsiquiatr 2007;65:599-604.

11. Obermann M, Gizewski ER, Limmroth V, Diener HC, Katsarava Z. Symptomatic migraine and potine vascular malformation: evidence for a key role of the brainstem in the pathophysiology of chronic migraine. Cephalalgia 2006;26:763-766. 